\title{
ESTIMATE OF RISK FACTORS AND THE PHYSICAL ENVIRONMENT TO THE BEHAVIORS OF TUBERCULOSIS INCIDENCE IN THE WORKING AREA OF SIDRAP
}

\section{Nama Penulis, ${ }^{1}$ Rahmi amir, ${ }^{1,2}$ Nurhanah Ibrahim $^{2}$}

${ }^{1}$ Universitas Muhammadiyah Parepare

\begin{abstract}
The World Health Organization (WHO) in the Annual Report on Global TB Control states that there are 22 countries categorized as high burden countris against Pulmonary TB, including Indonesia. The prevalence of pulmonary tuberculosis in Indonesia ranks third after India and China that is almost 700 thousand cases, the death rate is still 275/100 thousand inhabitants. Characteristics of rural areas become a determinant of the incidence of pulmonary $T B$ disease. The purpose of this study is how the estimation of physical environmental factors (home ventilation, humid environment, and occupancy density) is a risk factor for the incidence of TB Lung who live in the model stage house and How behavior factor estimation (Smoking, length of contact and stigma treatment) is a risk factor for the Lung TB incidence that resides in the stage model house.
\end{abstract}

This research is an observational research with case control study approach. Where the population in this study were all positive pulmonary tuberculosis patients and suspected pulmonary tuberculosis in the work area of puskesmas Bilokka. While the sample in this study is divided into two, namely the case of 30 people and control samples as many as 60 people with a ratio between case and control 1: 2. Data collection through interviews that refer to the questionnaire and observation directly, Data analysis using bivariate statistical test with Odss Ratio through SPSS Version 19 program.

Based on the results showed that the estimated risk factor proven as a risk factor for pulmonary TB incidence was the condition of ventilation (OR 13.02, 95\% CI: 3.25-71.50). And non-risk factors were density (OR 1.36, 95\% CI: 0.22-1.39), humid environment (OR 1.89, 95\% CI: 0.19-1.27), smoking behavior (OR 1.57, 95\% CI: 0.22-1,81), length of contact (OR 1.93, 95\% CI: 0.38-2.61), and stigma behavior was a protective factor with (OR 0 , 32, 95\% CI: 0.27-3.63).

Key words: Pulmonary TB, Risk Factors, ESTIMASI RESIKO DAN MODEL PENGEMBANGAN INTERVENSI KESEHATAN PADA PENDERITA TB PARU BERBASIS PSIKOEDUKASI(STUDI KASUS PADA PENDERITA YANG BERMUKIM PADA RUMAH MODEL PANGGUNG DISIDRAP SULAWESI SELATAN)

\begin{abstract}
Abstrak
World Health Organization (WHO) dalam Annual Report on Global TB Control menyatakan terdapat 22 negara yang dikategorikan sebagai high burden countris terhadap TB Paru, termasuk Indonesia. prevalensi TB Paru di Indonesia menempati urutan ketiga setelah India dan China yaitu hampir 700 ribu kasus, angka kematian masih tetap 275/100 ribu penduduk. Karakteristik wilayah pedesaan menjadi determinan tersendiri pada kejadian penyakit TB Paru.Tujuan penelitian ini adalah Bagaimana estimasi faktor lingkungan fisik (ventilasi rumah, lingkungan lembab, dan kepadatan hunian) merupakan faktor risiko terhadap kejadian Tb Paru yang bermukim pada rumah model panggung dan Bagaimana estimasi faktor perilaku (merokok, lama kontak dan perlakuan stigma) merupakan faktor risiko terhadap kejadian Tb Paru yang bermukim pada rumah model panggung.

Penelitian ini merupakan penelitian dalam bentuk observasional dengan pendekatan case control study. Dimana yang menjadi populasi dalam penelitian ini adalah seluruh penderita TB Paru positif dan suspek TB Paru di wilayah kerja puskesmas Bilokka. Sedangkan sampel dalam penelitian ini dibagi atas dua yaitu sampel kasus 30 orang dan sampel kontrol sebanyak 60 orang dengan perbandingan antara kasus dan kontrol 1:2. Pengumpulan data melalui wawancara
\end{abstract}

Korespondensi:Rahmi amir. Universitas Muhammadiyah Parepare Jl.jend akhmad Yani Km4, Kota Parepare, Provinsi sulawesi Selatan Faksimile:(o421-22757) HP: 085246913430 E-mail: 
yang mengacu pada kuesioner dan observasi secara langsung, Analisis data menggunakan uji statistik bivariat dengan Odss Ratio melalui program SPSS Versi 19.

Berdasarkan Hasil penelitian menujukkan bahwa estimasi faktor risiko yang terbukti sebagai faktor risiko kejadian TB Paru adalah kondisi ventilasi (OR 13,02,CI 95\%:3,25-71,50). Dan yang bukan faktor risiko adalah kepadatan hunian (OR 1,36,CI 95\%:0,22-1,39), lingkungan lembab (OR 1,89,CI 95\%:0,19-1,27), perilaku merokok (OR 1,57,CI 95\%:0,22-1,81), lama kontak (OR 1,93,CI 95\%:0,38-2,61), dan perilaku stigma merupakan faktor protektif dengan (OR 0,32,CI $95 \%: 0,27-3,63)$

Kata kunci: $\quad$ TB Paru, Faktor risiko

Korespondensi:Rahmi amir. Universitas Muhammadiyah Parepare Jl.jend akhmad Yani Km4, Kota Parepare, Provinsi sulawesi Selatan Faksimile:(o421-22757) HP: 085246913430 E-mail: 


\section{Introduction}

Tuberkulosis adalah suatu penyakit infeksi yang disebabkan oleh Mycobacterium Tuberkulosis dan bersifat menular (Christian, 2009). World Health Organization (WHO) menyatakan bahwa sepertiga penduduk dunia telah terinfeksi bakteri tuberkulosis . Setiap detik ada satu orang yang terinfeksi tuberkulosis.

Menurut laporan WHO tahun 2013, prevalensi TB Paru di Indonesia menempati urutan ketiga setelah India dan China yaitu hampir 700 ribu kasus, angka kematian masih tetap 27/100 ribu penduduk. Karakteristik wilayah pedesaan menjadi determinan tersendiri pada kejadian penyakit TB Paru.

Departemen Kesehatan (Depkes) RI (2006) menyatakan bahwa sekitar $75 \%$ pasien TB adalah kelompok usia yang paling produktif secara ekonomis (15-50 tahun), Di Indonesia, TB Paru merupakan masalah utama kesehatan masyarakat penyebab kematia nnomor 3 setelah penyakit kardiovaskuler dan penyakit pernafasan pada semua kelompok usia, dan nomor 1 dari golongan penyakit infeksi. secara kasar diperkirakan setiap 100.000 penduduk Indonesia terdapat 130 penderita baru tuberkulosis paru BTA positif.

Data kasus Tuberkulosis dari Riset Kesehatan Dasar/ Riskesdas tahun 2010 WHO menyebutkan prevelensi Tuberkulosis nasional 725/100.00o penduduk. Hasil menunjukkan pula 12 provinsi memiliki prevalensi Tuberkulosis diatas angka nasional 937/100.00o penduduk .

Jumlah penderita penyakit

tuberkulosis (TB) di Sulsel masih tinggi. Berdasarkan data Dinas Kesehatan (Dinkes) Provinsi, pada 2011, penderita penyakit menular ini mencapai 8.939 kasus. Angka ini meningkat signifikan dibanding tahun sebelumnya yang hanya 7.783 kasus. Kabupaten Takalar menduduki peringkat pertama dalam jumlah kasus dengan pertumbuhan penderita TBC di atas $109 \%$, menyusul Pare-pare 79\%, Pinrang 75 \%,disusul Makassar 70\% dan terendah Kabupaten Luwu 33 \% serta Sidrap 36 \%. Di kota Makassar, jumlah kasus yang suspek TB
Paru sekitar 13.701, BTA(+) sekitar 1.737 kasus, kambuh sekitar 92 kasus (Dinkes Prov. Sulsel, 2011).

Berdasarkan uraian di atas, penyakit Tuberkulosis merupakan salah satu penyakit dengan angka kesakitan dan angka kematian yang cukup tinggi, sehingga dalam penanganannya diperlukan kesadaran yang tinggi baik dari masyarakat maupun petugas, terutama tentang beberapa faktor yang mempengaruhi derajat kesehatan.

Selanjutnya Berdasarkan Laporan Penanggulangan Penderita Penyakit TB Paru Dinas Kesehatan Kabupaten Sidenreng Rappang Tahun 2011 sampai dengan tahun 2014, menunjukkan bahwa di Puskesmas Bilokka setiap tahunnya menempati salah satu Puskesmas urutan tertinggi jumlah penemuan penderita TB Paru dengan jumlah suspek sebanyak 366 suspek. Hal ini disebabkan karena kepadatan penduduk di wilayah kerja Puskesmas Bilokka sangat tinggi yaitu 18.442 jiwa. Selain itu tingginya jumlah perokok turut menyumbang meningkatnya jumlah penderita TB di Kabupaten Sidenreng Rappang khususnya wilayah kerja Puskesmas Bilokka setiap tahunnya.

Adapun rumusan masalahnya, sebagai berikut :

1. Bagaimana estimasi faktor lingkungan fisik (ventilasi rumah, lingkungan lembab, dan kepadatan hunian) merupakan faktor risiko terhadap kejadian Tb Paru yang bermukim pada rumah model panggung?

2. Bagaimana estimasi faktor perilaku (merokok, lama kontak dan perlakuan stigma) merupakan faktor risiko terhadap kejadian Tb Paru yang bermukim pada rumah model panggung ?

Adapun tujuan dalam penelitian ini adalah 1. Untuk mengaanlisis dan mengestimasi Apakah potensi faktor lingkungan fisik (ventilasi rumah, lingkungan lembab, dan kepadatan hunian) merupakan faktor risiko terhadap kejadian $\mathrm{Tb}$ Paru yang bermukim pada rumah panggung ?

2. Untuk mengaanlisis dan mengestimasi Apakah potensi faktor perilaku (merokok, lama kontak dan 
perlakuan stigma) merupakan faktor risiko terhadap kejadian Tb Paru yang bermukimpaa rumah panggung ?

Methods Jenis penelitian yang digunakan adalah penelitian observasional dengan rancangan kasus kontrol (case control study). Subyek penelitian ini terdiri dari dua, yaitu kelompok kasus dan kelompok kontrol dengan perbandingan 1 : 2 . Sampel pada penelitian ini sejumlah 30 orang yang positif TB Paru (kasus) dan 60 orang yang menjadi suspec TB Paru (kontrol) yang ada di wilayah kerja. Puskesmas Bilokka. Data primer diperoleh dengan cara melakukan wawancara langsung terhadap responden dengan yang mengacu pada kuesioner yang telah tersedia. Data sekunder diperoleh dari data yang telah ada sebelumnya. Dalam penelitian ini data sekunder diperoleh dari Dinas Kesehatan Kabupaten Sidrap dan
Puskesmas Perawatan Bilokka Kabupaten Sidrap. Selain itu data juga diperoleh melalui studi pustaka dan data berbasis elektronik

Pengolahan data yang dilakukan meliputi editing,coding,entry,cleaning dan tabulating. Analisis data yang dilakukan untuk penelitian ini menggunakan

Analisis univariat dan bivariat.Penelitian ini dilakukan di Kabupaten Sidenreng Rappang tepatnya di wilayah kerja Puskesmas Bilokka Kecamatan Panca Lautang

\section{Results}

Kelompok umur terbanyak adalah penderita TB Paru (kasus) dengan umur 44-58 tahun dan suspek TB Paru (kontrol) dengan jumlah terbanyak juga pada rentang umur 44-58 tahun 24 orang (40\%). Variabel jenis kelamin, tingkat pendidikan, pekerjaan bisa di lihat pada tabel 1

Tabel 1. Hasil Analisis Univariat variabel yang diteliti

\begin{tabular}{lcccc}
\hline \multirow{2}{*}{ Variabel } & \multicolumn{2}{c}{ Kasus } & \multicolumn{2}{c}{ Kontrol } \\
\cline { 2 - 5 } Kelompok Umur & Jumlah & \% & Jumlah & \% \\
12-27 & & & & \\
$28-43$ & 7 & 23,3 & 16 & 26,7 \\
$44-58$ & 11 & 36,7 & 20 & 33,3 \\
\hline Jenis Kelamin & 12 & 40,0 & 24 & 40,0 \\
Laki-laki & & & & \\
Perempuan & 17 & 56,7 & 33 & 55 \\
\hline Tingkat & 13 & 43,3 & 27 & 45 \\
Pendidikan & & & & \\
Tidak tamat SD & 2 & 6,7 & 7 & 11,7 \\
SD & 5 & 16,7 & 6 & 10 \\
SMP & 9 & 30 & 17 & 28,3 \\
SMA & 10 & 33,3 & 20 & 33,3 \\
Akademik/PT & 4 & 13,3 & 10 & 1,7 \\
\hline Pekerjaan & & & & \\
PNS & 3 & 10 & 10 & 16,7 \\
Pedagang & 8 & 26,7 & 10 & 16,7 \\
Petani & 9 & 30 & 9 & 15 \\
Wiraswasta & 4 & 13,3 & 19 & 31,7 \\
IRT & 6 & 20 & 12 & 20 \\
\hline Jumlah & 30 & 100 & 60 & 100 \\
\hline
\end{tabular}


Tabel 2. Hasil Analisis Univariat variabel yang diteliti

\begin{tabular}{lcccc}
\hline \multirow{2}{*}{ Variabel } & \multicolumn{4}{c}{ Kejadian TB Paru } \\
\cline { 2 - 5 } & \multicolumn{2}{c}{ Kasus } & Kontrol \\
\cline { 2 - 5 } Kondisi ventilasi & $\mathbf{N}$ & \% & & \% \\
Risiko tinggi & 23 & 76,7 & 29 & 48,3 \\
Risiko rendah & 7 & 23,3 & 31 & 51,7 \\
\hline Kepadatan hunian & & & & \\
Risiko tinggi & 13 & 43,3 & 18 & 30 \\
Risiko rendah & 17 & 56,7 & 42 & 70 \\
\hline Lingkungan lembab & & & & \\
Risiko tinggi & 12 & 40 & 15 & 25 \\
Risiko rendah & 18 & 60 & 45 & 75 \\
\hline Perilaku merokok & & & & \\
Risiko tinggi & 15 & 50 & 21 & 35 \\
Risiko rendah & 15 & 50 & 39 & 65 \\
\hline Perilaku Stigma & & & & \\
Risiko tinggi & 13 & 43,3 & 27 & 45 \\
Risiko rendah & 17 & 56,7 & 33 & 55 \\
\hline Jumlah & 30 & 100 & 60 & 100 \\
\hline
\end{tabular}

Tabel 3. Hasil Analisis Univariat variabel yang diteliti

\begin{tabular}{lcccc}
\hline \multirow{2}{*}{ Variabel penelitian } & P & OR & \multicolumn{2}{c}{$\mathbf{9 5 \% C I}$} \\
\cline { 4 - 5 } & & & LL & UL \\
\hline Kondisi ventilasi & 0,059 & 13,02 & 3,25 & 71,50 \\
Kepadatan hunian & 0,009 & 1,36 & 0,22 & 1,39 \\
Lingkungan lembab & 0,025 & 1,89 & 0,19 & 1,27 \\
Perilaku merokok & 0,003 & 1,57 & 0,22 & 1,81 \\
Perilaku stigma & 0,033 & 0,32 & 0,27 & 3,63 \\
\hline
\end{tabular}




\section{Discussion}

Berdasarkan variabel-variabel yang telah diteliti pada faktor lingkungan fisik kondisi ventilasi menujukkan adanya risiko terhadap kejadian TB Paru, sedangkan kepadatan hunian, kelembapan lingkungan, perilaku merokok, lama kontak tidak menunjukkan adanya faktor risiko dan perilaku stigma merupakan faktor protektif.

Hasil uji statistik (Tabel 3) menunjukkan bahwa Berdasarkan hasil analisis Odds Ratio di peroleh $\mathrm{OR}=13,02$ dengan nilai lower limit 3,25 dan upper limit 71,50. karena nilai OR > 1, maka kondisi ventilasi merupakan faktor risiko terhadap kejadian TB Paru di wilayah kerja Puskesmas Bilokka. Hasil penelitian ini sejalan dengan penelitian Sitti Fatimah (2008) yang mengatakan bahwa kondisi ventilasi mempunyai risiko sebesar 14,57 kali dibandingkan dengan responden dengan ventilasi yang memenuhi syarat.

Menurut Rusnoto et al. (2005) bahwa adanya hubungan yang bermakna antara luas ventilasi dengan kejadian tuberkulosis paru, didapatkan hasil odds ratio (OR) sebesar 16,9 dengan 95 \% Confidence Interval (CI) 2,121134,641, dengan nilai $\mathrm{p}=0$,o01.

Berdasarkan hasil analisis Odds Ratio (OR) terhadap kepadatan hunian didapatkan OR sebesar 1,36 pada tingkat kepercayaan $(\mathrm{CI})=95 \%$ dengan lower limit 0,22 dan upper limit $=1,39$. karena nilai $\mathrm{OR}=1$, maka Kepadatan hunian bukan merupakan faktor risiko terhadap kejadian TB Paru di wilayah kerja Puskesmas Bilokka. Hal ini sesuai dengan penelitian Afnal Asrifuddin 2011 yang juga menyatakan bahwa kepadatan penghuni tidak berisiko terhadap kejadian TB Paru.

Berdasarkan hasil analisis Odds Ratio (OR) terhadap lingkungan lembab didapatkan OR sebesar 1,89 pada tingkat kepercayaan $(\mathrm{CI})=95 \%$ dengan lower limit $=0,19$ dan upper limit $=1,27$. karena nilai $\mathrm{OR}=1$, maka lingkungan lembab bukan merupakan faktor risiko terhadap kejadian TB Paru di wilayah kerja Puskesmas Bilokka. Dengan demikian , responden yang memiliki kelembapan lingkungan dengan risiko tinggi memiliki 1,89 kali lebih besar untuk menderita penyakit TB Paru bila dibandingkan dengan responden yang memiliki kelembapan hunian dengan risiko rendah.

Hal ini sesuai dengan penelitian Priyadi S 2003 yang juga menemukan bahwa OR kelembapan lingkungan mempunyai risiko 2,57 kali lebih tinggi untuk terkena TB Paru dibandingkan dengan responden dengan kelembapan yang baik

Berdasarkan hasil analisis Odds Ratio (OR) terhadap perilaku merokok didapatkan OR sebesar 1,57 pada tingkat kepercayaan $(\mathrm{CI})=95 \%$ dengan lower limit $=0,22$ dan upper limit $=1,81$. karena nilai $\mathrm{OR}=1$, maka perilaku merokok bukan merupakan faktor risiko terhadap kejadian TB Paru di wilayah kerja Puskesmas Bilokka. Dengan demikian, responden yang memiliki perilaku merokok dengan nilai komposit rokok $\geq 200$ memiliki 1,57 kali lebih besar untuk menderita penyakit TB Paru bila dibandingkan dengan responden yang memiliki perilaku merokok dengan nilai komposit rokok $<200$, atau dapat disimpulkan bahwa perilaku merokok bukan faktor risiko terhadap kejadian TB Paru. Hal ini sesuai dengan penelitian Tri martiana,dkk 2007 yang juga menemukan bahwa OR perilaku merokok mempunyai risiko 0,19 kali lebih tinggi untuk terkena TB Paru dibandingkan dibandingkan dengan responden yang memiliki nilai kompisit rokok < 200 batang.

Berdasarkan hasil analisis Odds Ratio (OR) terhadap lama kontak didapatkan OR sebesar 1,93 pada tingkat kepercayaan $(\mathrm{CI})=95 \%$ dengan lower limit $=0,38$ dan upper limit $=2,61$. karena nilai $\mathrm{OR}=1$, maka lama kontak bukan merupakan faktor risiko terhadap kejadian $\mathrm{TB}$ Paru di wilayah kerja Puskesmas Bilokka. Dengan demikian, responden yang memiliki lama kontak $\geq 6$ bulan memiliki 1,93 kali lebih besar untuk menderita penyakit TB Paru bila dibandingkan dengan responden yang memiliki lama kontak $<6$ bulan, atau dapat

disimpulkan bahwa lama kontak bukan faktor risiko terhadap kejadian TB Paru. Hasil penelitian ini sejalan dengan penelitian Beni (2003) yang mengatakan bahwa orang yang kontak dengan penderita TB Paru > 6 bulan akan mempunyai risiko sebesar 2,56 kali untuk terjadinya TB Paru dibandingkan dengan orang tdak memiliki lama kontak dengan penderita TB Paru.

Berdasarkan hasil analisis Odds Ratio (OR) terhadap perilaku stigma didapatkan OR sebesar 0,32 pada tingkat kepercayaan (CI) $=95 \%$ dengan lower limit $=0,27$ dan upper limit $=3,63$. karena nilai OR $<1$, maka perilaku Stigma merupakan faktor protektif terhadap kejadian TB Paru di wilayah kerja Puskesmas Bilokka. Dengan demikian, responden yang mendapatkan stigma dari keluarga atau masyarakat memiliki o,32 kali lebih besar untuk menderita penyakit TB Paru bila dibandingkan dengan responden yang tidak mendapatkan perlakuan stigma dari keluarga atau masyarakat, atau dapat disimpulkan bahwa 
perilaku stigma bukan faktor risiko terhadap kejadian TB Paru. Hasil penelitian ini didukung oleh penelitian Rossy (2005) dimana dari 84 responden diperoleh sebanyak 14,5\% mendapatkan stigma dari masyarakat.

\section{Conclusion}

Penelitian ini telah menemukan bahwa Kondisi ventilasi merupakan faktor risiko terhadap kejadian TB Paru. Kepadatan hunian, kelembapan lingkungan, perilaku merokok lama kontak bukan merupakan faktor risiko terhadap kejadian TB Paru . Sedangkan perilaku Stigma merupakan faktor protektif terhadap kejadian tuberkulosis. Di harapkan kepada masyarakat yang ingin membangun rumah agar selalu memperhatikan syarat- syarat rumah sehat terutama kondisi ventilasi serta kondisi lingkungan sekitarnya. Untuk mengurangi resiko penularan TB Paru, agar dilakukan perbaikan kondisi lingkungan rumah, mengurangi kelembaban ruangan dan memperhatikan aspek sanitasi rumah sehat seperti ventilasi. Penderita TB paru harus di beri motivasi dari keluarga terhadap stigma yang didapatkan agar penderita tidak merasa terkucilkan dan terdorong untuk melakukan pengobatan. Dan untuk penelitian selanjutnya bisa menambahkan variabel status gizi terhadap kejadian Tuberkulosis paru dan menggunakan sampel yang lebih banyak lagi

\section{References}

1. Amu. 2007. Hubungan Merokok dan Penyakit Tuberkulosis Paru. Jakarta : Jurnal Tuberkulosis Indonesia Vol 5 hal 57.

2. Azwar. 2005.Perilaku Kesehatan Masyarakat.Jakarta : Rineka Cipta

3. Asrifuddin A.2011. Analisis Faktor Risiko Kejadian Infeksi Opportunistik TB Paru pada Penderita HIV/AIDS di RSUP DR W ahidin Sudirohusodo Makassar.Tesis.Makassar : Unhas

4. Amelda L. 2012. Hubungan antara Pekerjaan,PMO, Pelayanan Kesehatan, dan Dukungan
5. Binongko A. 2012 . Laporan Surveilance Epidemiologi Penyakit Tuberkulosis di Puskesmas Wajo Kota Baubau. [akses 13 Maret 2015]

6. [Dinkes] Dinas Kesehatan Provinsi Sulawesi Selatan, 2009. Profil Kesehatan Sulawesi Selatan. http://www.datinkessulsel.wordpress.com . [akses 14 Maret 2015].

7. Firdiana P. 2008 . Hubungan antara Luas Ventilasi dan Pencahayaan Rumah dengan Kejadian Tuberkulosis Paru di Wilayah kerja Puskesmas Kedungmundu Kecamatan Temba;ang Semarang tahun 2007. Jurnal kesehatan masyarakat volume 3/ no 2/ januari- juni 2008.

8. Wajdi, Halim, Soebijanto, Irawati, Susi, 2005, Kesehatan Lingkungan Rumah dan Kejadian Penyakit TB Paru di Kabupaten Agam Sumatra Barat, Jurnal Sains Kesehatan UGM, Jogyakarta. [ akses 23 Maret 2017].

9. Wijaya, A.A. 2012. Merokok dan Tuberkulosis. Jurnal Tuberkulosis Indonesia, vol 8, Jakarta : PPTI. [akses 23 Maret 2017].

10. [WHO] World Health Organization Report 2013- Global Tuberkulosis Control, www.who.int/tb/data. [akses tangaal 25 Maret 2017]. 
